\title{
Dexmedetomidine versus remifentanil for sedation during awake intubation using a Shikani optical stylet: a randomized, double-blinded, controlled trial
}

Ting Xu, Min Li ${ }^{*}$, Cheng Ni and Xiang-yang Guo

\begin{abstract}
Background: The purpose of this study was to compare the efficacy and safety of dexmedetomidine versus remifentanil for sedation during awake intubation using a Shikani optical stylet (SOS).

Methods: Sixty-eight patients with cervical trauma or severe cervical spondylosis undergoing cervical spinal surgery were enrolled in this prospective study. They were randomly assigned to receive dexmedetomidine (Group D) or remifentanil (Group R). In Group D, the patients received an intravenous loading dose of dexmedetomidine $1 \mu \mathrm{g}$. $\mathrm{kg}^{-1}$ over 10 min followed by a continuous infusion of $0.7 \mu \mathrm{g} \cdot \mathrm{kg}^{-1} \cdot \mathrm{h}^{-1}$. In Group R, a target-controlled infusion of remifentanil was administered to achieve a plasma concentration of $2.5 \mathrm{ng} \cdot \mathrm{ml}^{-1}$, increased to $3 \mathrm{ng} \cdot \mathrm{ml}^{-1} 10 \mathrm{~min}$ later. An endotracheal tube was inserted using a SOS under dexmedetomidine or remifentanil sedation after topical anesthesia to the airway. Midazolam was given as rescue sedation. We recorded the first attempt intubation success rate, the dose of midazolam, duration of intubation, Ramsay Sedation Scale (RSS) score, tracheal tube tolerance score, duration of drug infusion, adverse events and patient satisfaction score.
\end{abstract}

Results: The RSS score was significantly higher in Group D than in Group R. First attempt success rate, rescue midazolam dose and the duration of intubation did not differ between the groups. Patients in Group R were significantly more tolerant of the tracheal tube. The incidence of hypoxia was significantly higher in Group R than Group D, but there was no significant difference in the incidence of other adverse events between the groups. The hemodynamic responses of the two groups were similar, but more patients in Group R were able to recall airway instrumentation.

Conclusions: Both dexmedetomidine and remifentanil are effective sedatives for awake intubation using an SOS. Although the first attempt success rates were similar, patients sedated with remifentanil tolerated the tracheal tube better after intubation with moderately increased risk of desaturation.

Trial registration: www.chictr.org.cn; ChiCTR-TRC-13003052 (February 4th, 2013).

Keywords: Dexmedetomidine, Remifentanil, Shikani optical stylet, Awake intubation, Sedation

* Correspondence: liminanesth@aliyun.com

Department of Anesthesiology, Peking University Third Hospital, Beijing 100191, China

(C) 2016 Xu et al. Open Access This article is distributed under the terms of the Creative Commons Attribution 40 


\section{Background}

The Shikani optical stylet ${ }^{\mathrm{Tm}}$ (SOS; Clarus Medical, Minneapolis, MN, USA) is a rigid but malleable stylet with fiberoptic rods and a lens. The SOS is an effective means of managing patients with a difficult airway [1-6]. Compared with a Macintosh laryngoscope, use of a SOS reportedly reduces cervical spine movement during intubation [7], suggesting that it might reduce the risk of spinal cord injury during instrumentation of the airway in patients with a potential or documented cervical spine injury.

The SOS is most often used to intubate patients under general anesthesia. Awake intubation using the SOS in a patient with a difficult airway has been reported in two cases $[3,8]$. The best means of providing sedation in awake SOS intubation has not yet been established. Sedation is one of the key elements for successful awake intubation. Intravenous midazolam, propofol and remifentanil are commonly used as sedatives for awake fiberoptic endoscope intubation (AFOI), and there have been recent reports of the safe and effective use of dexmedetomidine [9-14]. Dexmedetomidine is a highly selective $\alpha_{2}$ adrenoceptor agonist that acts as a sedative, analgesic and a moderate antisialagogue without respiratory depression, suggesting that it could be a suitable drug for facilitating awake intubation. Previous studies have demonstrated that dexmedetomidine is superior to midazolam [13], fentanyl [15], propofol [16] and sufentanil [17] in AFOI. Two studies compared dexmedetomidine with remifentanil for AFOI, but their results were contradictory $[9,10]$.

The sedation regimen for AFOI might not be suitable for awake intubation when a SOS is used instead of a fiberoptic bronchoscope (FOB), as the two devices have different characteristics and are manipulated differently. This study was designed to compare the efficacy and safety of dexmedetomidine with that of remifentanil during awake intubation with a SOS.

\section{Methods}

After institutional ethics committee approval (IRB000067612012045, Medical Ethics Committee of Peking University Third Hospital), informed written consent was obtained from all patients. We enrolled patients between December 2013 and December 2014. Inclusion criteria were: age 1870 years; American Society of Anesthesiologists (ASA) physical status score I-III; requirement for preoperative neck immobilization with a hard plastic collar; planned urgent or elective cervical spine surgery for cervical trauma or severe cervical spondylosis. Exclusion criteria were: pregnancy; use of an $\alpha_{2}$ adrenoreceptor agonist or antagonist within the previous 14 days; known or admitted alcohol or drug misuse; uncontrolled seizure disorder; history of unstable angina or myocardial infarction; resting heart rate $(\mathrm{HR})<50 \mathrm{~min}^{-1}$; and complete heart block.
Patients were assigned by a computer-generated randomization schedule to receive sedation with dexmedetomidine (Group D) or remifentanil (Group R). A research nurse generated the allocation sequence, enrolled participants and assigned them to their groups. While one anesthesiologist prepared and infused the study drug, another anesthesiologist experienced in the use of the SOS was in charge of airway anesthesia and intubation. Another research nurse assessed the patients, recorded intubation time and followed up the patients postoperatively. The participants, the intubating anesthesiologist and the nurse who was responsible for assessment and follow up were blinded to the group allocation.

All patients received a bolus of intravenous scopolamine $0.3 \mathrm{mg}$ as premedication and oxygen by nasal cannula $\left(3 \mathrm{~L} \cdot \mathrm{min}^{-1}\right)$. Vital signs, including systolic blood pressure (SBP), diastolic blood pressure (DBP), HR and pulse oxygen saturation $\left(\mathrm{SpO}_{2}\right)$ were recorded at baseline and every 2 min until the completion of intubation. The time required for intubation (from the first insertion of the SOS to confirming intubation with capnography) and the number of attempts was also recorded.

All patients received the study drug via an Alaris PK Syringe Pump (Care Fusion, Becton Dickinson, Franklin Lakes, NJ). The study drug was diluted to $50 \mathrm{~mL}$ with a $0.9 \% \mathrm{NaCl}$ solution, and the infusion was started $10 \mathrm{~min}$ before airway anesthesia and continued throughout airway management and intubation. Group D received a loading dose of $1.0 \mu \mathrm{g} \cdot \mathrm{kg}^{-1}$ dexmedetomidine over $10 \mathrm{~min}$ followed by a continuous infusion of $0.7 \mu \mathrm{g} \cdot \mathrm{kg}^{-1} \cdot \mathrm{h}^{-1}$ [12]. Group $\mathrm{R}$ received a target-controlled infusion of remifentanil using the Minto three compartment model. The initial target was set at $2.5 \mathrm{ng} \cdot \mathrm{ml}^{-1}$ and increased to $3 \mathrm{ng} \cdot \mathrm{ml}^{-1}$ 10 min later. In both groups, the drug infusion was continued until confirmation of successful intubation.

During application of topical airway anesthesia and intubation, the cervical collar was not released. Airway anesthesia began $10 \mathrm{~min}$ after the start of sedative drug infusion. Lidocaine $200 \mathrm{mg}$ was administered through a laryngotracheal mucosa atomization device (LMA MADgic, Teleflex Medical, Athlone, Republic of Ireland) to the mouth, larynx and glottis.

The application of topical anesthesia to the upper airway took no less than $10 \mathrm{~min}$. The patient's sedation level was assessed using the Ramsay Sedation Scale (RSS) at baseline, $10 \mathrm{~min}$ after the drug infusion had started, and every $3 \mathrm{~min}$ during airway anesthesia. Any patient with an RSS $<2$ was given a rescue bolus of intravenous midazolam $0.5 \mathrm{mg}$ until an RSS of 2 was achieved [12].

A SOS preloaded with an endotracheal tube (ETT) was inserted over the tongue. The supine patient was asked to take deep breaths. The epiglottis and the glottic opening were identified via the eyepiece. Once the vocal cords were visualized, the tip of the ETT was advanced 
during inspiration. After the tip of ETT had entered the trachea, the SOS was withdrawn. Intubation score was assessed using a 5-point scale during SOS endoscopy and intubation (1, no movement; 2 , grimacing; 3 , mild cough; 4, major limb movement; 5, prolonged coughing) [13]. If the intubation score was $>2$ during endoscopy, the SOS was withdrawn and $3 \mathrm{~mL} 2 \%$ lidocaine was sprayed on to the glottis via the LMA MADgic. The patient's sedation level was reassessed and rescue midazolam $0.5 \mathrm{mg}$ was given repeatedly in 1-min intervals until RSS $\geq 2$.

The SOS was withdrawn if the patient's $\mathrm{SpO}_{2}$ was $\leq 92 \%$ during endoscopy. Oxygen was given via facemask $(5 \mathrm{~L}$. $\mathrm{min}^{-1}$ ) and the patient was instructed to take deep breaths. When $\mathrm{SpO}_{2}$ recovered to $\geq 95 \%$, another intubation attempt was made.

Immediately after intubation, end tidal $\mathrm{CO}_{2}$ concentration (first breath) was recorded. Tolerance of the ETT was assessed using a 3-point scale (1, well tolerated and cooperative; 2 , mild coughing and/or grimacing but still cooperative; 3, severe coughing and/or agitated and not cooperative) [15]. General anesthesia was induced immediately after assessment of ETT tolerance. Infusion of the study drug was discontinued upon completion of induction of general anesthesia.

At the 24-h postoperative follow-up visit, patients were interviewed to assess their recall of pre-anesthesia events, administration of topical anesthesia, endoscopy and intubation, and whether there had been complications (for example, injury to the teeth, lip or oral mucosa, sore throat or hoarseness). Patient satisfaction with the whole procedure was assessed on an 11-point numeric rating scale $(0$, completely dissatisfied; 10 , completely satisfied).

The primary efficacy endpoint of this study was the proportion of patients intubated successfully at the first attempt. Based on the findings of a previous study, in which the first attempt success rates using dexmedetomidine versus remifentanil in AFOI were 38 and $76 \%$ respectively [10], we calculated that a sample size of 64 patients would be sufficient to detect a difference between the treatment groups with a power of 0.8 and a significance level of 0.05 . Considering possible $5 \%$ dropout, the sample size was set at 68 .

We used SPSS 13.0 software (SPSS, Chicago, IL) for statistical analyses. Continuous variables are expressed as mean \pm standard deviation, and were compared within groups using the paired $t$-test and between groups using the independent $t$-test. The chi-squared test or Fisher's exact test were used to compare categorical data between the groups. Intubation conditions and tolerance score were analyzed using the independent samples Mann-Whitney $U$ test. Blood pressure and HR at different time points were compared using two-way repeatedmeasures analysis of variance. A $P$ value $<0.05$ was regarded as statistically significant.

\section{Results}

A total of 70 patients were assessed for eligibility, and 68 patients were enrolled. The enrolled patients were randomized and all of them completed this study (Fig. 1). Patients' demographic and clinical characteristics did not differ between the groups (Table 1).

The baseline RSS of the two groups were similar (Table 2), but RSS was significantly higher in Group D than in Group R 10 min after drug infusion (Table $2, P=0.001$ ).

All patients were successfully intubated with the SOS. The first intubation attempt success rates and the need for rescue midazolam were similar between the groups (Table 2). In first-time SOS insertions, the intubation scores of the two groups were broadly comparable. After intubation, mild coughing was observed in 12 patients in Group R, compared with 24 patients in Group D (and one case of severe coughing), resulting in significantly different tube tolerance scores $(P=0.001)$. The duration of drug infusion was $26.0 \pm 4.5$ versus $24.8 \pm 4.0 \mathrm{~min}$ in Groups D and R, respectively $(P=0.247)$.

Nine patients in Group R and two in Group D developed hypoxia during intubation. The incidence of hypoxia (defined as $\mathrm{SpO}_{2} \leq 90 \%$ or a decrease of $10 \%$ below baseline saturation, with the number of desaturation episodes measured on a per patient basis) in Group $\mathrm{R}$ was significantly higher than Group D ( $26 \%$ versus $6 \%, P=0.021)$. The lowest $\mathrm{SpO}_{2}$, observed in a patient in Group R, was $85 \%$. All patients who developed hypoxia recovered to an $\mathrm{SpO}_{2} \geq$ $95 \%$ within 2 min after administration of supplementary oxygen by face mask. The hemodynamic changes observed in both groups were similar (Table 3). There were no significant differences in the occurrence of hemodynamic adverse events between the groups from the beginning of drug infusion until 10 min after intubation (Table 4). Significantly more patients in Group $\mathrm{R}$ recalled airway management than Group D (Table 2). There were no significant

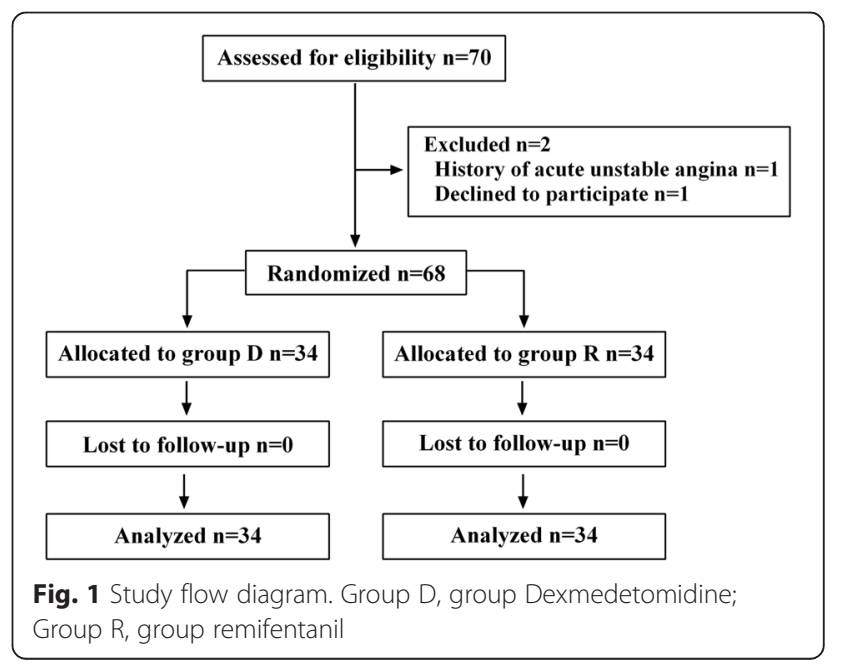


Table 1 Demographic and clinical characteristics of study participants

\begin{tabular}{llll}
\hline Characteristic & $\begin{array}{l}\text { Group D } \\
(n=34)\end{array}$ & $\begin{array}{l}\text { Group R } \\
(n=34)\end{array}$ & $P$ value \\
\hline Age (years) & $52.9 \pm 10.0$ & $50.9 \pm 9.4$ & 0.412 \\
Sex (male/female) & $18(53) / 16(47)$ & $21(62) / 13(38)$ & 0.462 \\
Cervical trauma/ & $15(44) / 19(56)$ & $18(53) / 16(47)$ & 0.467 \\
cervical spondylosis & & & \\
ASA status (I, II or III) & $10(29) / 22(65) / 2(6)$ & $14(41) / 17(50) / 3(9)$ & 0.958 \\
Mallampatti grade & $9(26) / 16(47) / 8$ & $8(24) / 18(53) / 6$ & 0.947 \\
$(1,2,3$ or 4) & $(24) / 1(3)$ & $(18) / 2(6)$ & \\
BMI (kg $\left.\cdot \mathrm{m}^{-2}\right)$ & $25.5 \pm 3.9$ & $25.3 \pm 3.3$ & 0.864 \\
Mouth opening (cm) & $4.7 \pm 0.7$ & $4.6 \pm 0.9$ & 0.928 \\
\hline
\end{tabular}

Data are presented as mean \pm standard deviation or number (proportion, \%) Abbreviations: BMI body mass index, ASA American Society of Anesthesiologists

differences in patient satisfaction (Table 2) or intubation complications between the two groups (Table 4).

\section{Discussion}

We found that remifentanil and dexmedetomidine are both suitable for use as sedatives for awake SOS intubation. Although the first attempt success rates were similar between the groups, patients sedated with remifentanil

Table 2 Airway management characteristics

\begin{tabular}{|c|c|c|c|}
\hline & $\begin{array}{l}\text { Group D } \\
(n=34)\end{array}$ & $\begin{array}{l}\text { Group R } \\
(n=34)\end{array}$ & $P$ value \\
\hline $\begin{array}{l}\text { RSS } 10 \text { min after start } \\
\text { of drug infusion }\end{array}$ & $3(2,4)$ & $2(2,4)$ & 0.001 \\
\hline $\begin{array}{l}\text { Intubation score at } \\
\text { first attempt }\end{array}$ & $2(1,4)$ & $2(1,3)$ & 0.119 \\
\hline $\begin{array}{l}\text { First intubation attempt } \\
\text { success rate (\%) }\end{array}$ & 79.4 & 85.3 & 0.525 \\
\hline $\begin{array}{l}\text { Intubation attempts } \\
(1 / 2 / 3 / 4)\end{array}$ & $\begin{array}{l}27(79) / 0 / 5(15) / \\
2(6)\end{array}$ & $\begin{array}{l}29(85) / 1(3) / \\
4(12) / 0\end{array}$ & 0.442 \\
\hline $\begin{array}{l}\text { Cumulative dose of } \\
\text { midazolam (mg) }\end{array}$ & $1.1 \pm 0.2$ & $0.9 \pm 0.2$ & 0.109 \\
\hline $\begin{array}{l}\text { Duration of drug } \\
\text { infusion (min) }\end{array}$ & $26.0 \pm 4.5$ & $24.8 \pm 4.0$ & 0.247 \\
\hline Duration of intubation(s) & $107 \pm 153$ & $76 \pm 106$ & 0.342 \\
\hline $\begin{array}{l}\text { Tolerance of endotracheal } \\
\text { tube }(1 / 2 / 3)\end{array}$ & $9(26) / 24(71) / 1(3)$ & $22(65) / 12(35) / 0$ & 0.001 \\
\hline First $\mathrm{P}_{\mathrm{ET}} \mathrm{CO}_{2}\left(\mathrm{cmH}_{2} \mathrm{O}\right)$ & $36.3 \pm 4.0$ & $36.4 \pm 3.5$ & 0.897 \\
\hline \multicolumn{4}{|l|}{ Incidence of recall } \\
\hline Pre-anesthesia events & $34(100)$ & $34(100)$ & 1.000 \\
\hline Topical anesthesia & $29(85)$ & $34(100)$ & 0.020 \\
\hline Endoscopy & $20(59)$ & $33(97)$ & 0.000 \\
\hline Intubation & $8(34)$ & $26(64)$ & 0.000 \\
\hline Patient satisfaction score & $7.9 \pm 0.8$ & $7.9 \pm 1.0$ & 0.792 \\
\hline
\end{tabular}

Data are presented as median (minimum, maximum), mean \pm standard deviation or number (proportion, \%)

Abbreviations: RSS Ramsey sedation score, $\mathrm{P}_{E T} \mathrm{CO}_{2} \%$ end tidal carbon dioxide
Table 3 Hemodynamic changes during intubation $(n=34)$

\begin{tabular}{lllllll}
\hline Index & Group & T1 & T2 & T3 & T4 & $\begin{array}{l}P_{\text {(between }} \\
\text { groups) }\end{array}$ \\
\hline SBP $(\mathrm{mmHg})$ & $\mathrm{D}$ & $130 \pm 18$ & $120 \pm 18$ & $127 \pm 30$ & $148 \pm 16$ & 0.630 \\
& $\mathrm{R}$ & $131 \pm 14$ & $122 \pm 14$ & $125 \pm 15$ & $137 \pm 13$ & \\
DBP $(\mathrm{mmHg})$ & $\mathrm{D}$ & $77 \pm 13$ & $72 \pm 11$ & $75 \pm 11$ & $87 \pm 12$ & 0.761 \\
& $\mathrm{R}$ & $79 \pm 10$ & $73 \pm 13$ & $74 \pm 12$ & $82 \pm 13$ & \\
HR $\left(\mathrm{min}^{-1}\right)$ & $\mathrm{D}$ & $79 \pm 16$ & $72 \pm 16$ & $78 \pm 15$ & $86 \pm 14$ & 0.682 \\
& $\mathrm{R}$ & $76 \pm 12$ & $72 \pm 12$ & $77 \pm 11$ & $85 \pm 12$ & \\
\hline
\end{tabular}

Data are presented as mean \pm standard deviation. $\mathrm{T} 1$, baseline; $\mathrm{T} 2,10 \mathrm{~min}$ after study drug infusion; T3, pre-intubation; T4, 1 min after intubation

Abbreviations: $S B P$ systolic blood pressure, $D B P$ diastolic blood pressure, $H R$ heart rate

tolerated the tracheal tube better after intubation, but at the expense of a greater risk of mild desaturation.

We selected the dose of the sedative according to previous studies of AFOI. The loading dose of $1 \mu \mathrm{g} \cdot \mathrm{kg}^{-1}$ over $10 \mathrm{~min}$ followed by a continuous infusion at 0.5 $0.7 \mu \mathrm{g} \cdot \mathrm{kg}^{-1} \cdot \mathrm{h}^{-1}$ is a standard regime for intraoperative use of dexmedetomidine, and is most widely reported in use for dexmedetomidine sedation for AFOI [12, 16-21]. A higher dose may cause hypertension [22], while a lower one may not achieve adequate sedation. The reported target concentrations of remifentanil for AFOI vary $[9,10,23-30]$; in most studies the target effect site concentration of remifentanil at the time of endotracheal intubation was $2-4 \mathrm{ng} \cdot \mathrm{ml}^{-1}[9,10,23-28,30]$. This informed our choice of $3 \mathrm{ng} \cdot \mathrm{ml}^{-1}$.

We found that the main differences between the groups were sedation level and ETT tolerance. The patients in Group D were more deeply sedated, but patients in both groups were able to cooperate with the

Table 4 Adverse events during airway management

\begin{tabular}{llll}
\hline Adverse event & $\mathrm{D}$ & $\mathrm{R}$ & $P$-value \\
\hline Hypotension & $3(8.8)$ & $1(2.9)$ & 0.303 \\
Hypertension & $3(8.8)$ & $6(17.6)$ & 0.283 \\
Tachycardia & $7(20.6)$ & $9(26.5)$ & 0.567 \\
Bradycardia & $2(5.9)$ & $0(0)$ & 0.151 \\
Hypoxia & $2(5.9)$ & $9(26.5)$ & 0.021 \\
Loosening of teeth & $0(0)$ & $0(0)$ & 1.000 \\
Injury to lip or oral mucosa & $0(0)$ & $0(0)$ & 1.000 \\
Postoperative sore throat & $16(47.1)$ & $18(52.9)$ & 0.628 \\
Hoarseness & $2(5.9)$ & $2(5.9)$ & 1.000
\end{tabular}

Data are given as number (proportion, \%). Baseline values of systolic blood pressure (SBP), diastolic blood pressure (DBP) and peripheral oxygen saturation $\left(\mathrm{SpO}_{2}\right)$ were used to define adverse events. Hypotension was defined as SBP $<80 \mathrm{mmHg}$, DBP $<50 \mathrm{mmHg}$ or SBP decreased $\leq 30 \%$ below baseline values. Hypertension was defined as SBP $>180 \mathrm{mmHg}$, DBP $>100 \mathrm{mmHg}$ or an SBP increased $\geq 30 \%$ higher than baseline values. Bradycardia was defined as $\mathrm{HR}<45 \mathrm{~min}^{-1}$ or a decrease to $\leq 30 \%$ below baseline. Tachycardia was defined as HR $>120 \mathrm{~min}^{-1}$ or an increased $\geq 30 \%$ higher than baseline values. Hypoxia was defined as $\mathrm{SpO}_{2} \leq 90 \%$ or a decrease by $\geq 10 \%$ of the baseline saturation 
operator during airway anesthesia. There were no significant differences in the first intubation attempt success rates or the overall score for intubation conditions at the first attempt between the groups. After intubation, the proportion of patients who coughed mildly in Group D was twice that of Group R. Although patients in Group D were significantly less likely to tolerate the ETT, there was nonetheless no difference in the proportion with hypertension or tachycardia compared with Group R. The apparent lack of a profound hemodynamic response to coughing and the higher incidence of bradycardia in Group D may be explained by the anti-sympathetic effect of dexmedetomidine.

In contrast, $\mathrm{Hu}$ and colleagues found that dexmedetomidine and remifentanil were both effective in patients undergoing awake fiberoptic nasotracheal intubation, and there were no significant differences in intubation or postintubation scores between those sedated with dexmedetomidine versus remifentanil [9]. Unlike a flexible FOB, the SOS is a more rigid rod with limited degrees of freedom. This difference makes the manipulation of the SOS more stimulating than a FOB. Additionally, the SOS does not have a working channel though which local anesthetic can be administered in a 'spray-as-you-go' manner. Although the vocal cords and the airway above the vocal cords can be adequately anesthetized through an LMA MADgic, local anesthetic could not be sprayed into the trachea. The suppression of the cough reflex after intubation relied mainly on the analgesic properties of the sedative.

There have been several reports of the use of dexmedetomidine or remifentanil for AFOI without topical anesthesia. In one case report, a loading dose of $1.0 \mu \mathrm{g}$. $\mathrm{kg}^{-1}$ dexmedetomidine followed by an infusion of $0.6 \mu \mathrm{g}$. $\mathrm{kg}^{-1} \cdot \mathrm{h}^{-1}$ was used as the sole agent for AFIO in a patient with local anesthetic allergy [18]. The authors reported that the patient tolerated the procedure well with minimal discomfort despite the lack of topical anesthesia.
Our findings suggest that for awake SOS intubation a combination of dexmedetomidine with a more potent analgesic drug should be considered to achieve better ETT tolerance. A recent study showed that for AFOI, the use of dexmedetomidine $\left(1 \mu \mathrm{g} \cdot \mathrm{kg}^{-1}\right.$ loading dose followed by an infusion of $\left.0.5 \mu \mathrm{g} \cdot \mathrm{kg}^{-1} \cdot \mathrm{h}^{-1}\right)$ plus ketamine $(15 \mathrm{mg}$ loading dose and a $20 \mathrm{mg} \cdot \mathrm{h}^{-1}$ continuous infusion) provided better hemodynamic stability and sedation than dexmedetomidine alone [31].

The proportion of patients in our study who experienced mild or prolonged coughing after intubation was significantly lower in Group R than Group D. In a previous study, Song and colleagues used 'no sustained and repetitive coughing with head lift' as the indicator of suitable sedation conditions for AFIO in patients undergoing cervical spine surgery [28]. Although in our study,all patients in Group $\mathrm{R}$ met Song's criteria, a higher plasma remifentanil concentration might reduce the incidence of mild coughing further. Vennila and colleagues used a target controlled infusion of remifentanil as the sole agent for AFIO without 'spray-as-you-go' local anesthesia [29]. The higher mean remifentanil concentration that they adopted $\left(6.3 \mathrm{ng} \cdot \mathrm{ml}^{-1}\right.$ at nasal endoscopy, and $8.06 \mathrm{ng} \cdot \mathrm{ml}^{-1}$ during tracheal intubation) was shown to be safe. Although in the present study, Group R had a higher incidence of hypoxia, the degree of hypoxia was modest-the lowest $\mathrm{SpO}_{2}$ was $85 \%$ in one patient. Hypoxia was successfully addressed within $2 \mathrm{~min}$ in all patients who desaturated. The majority of patients who developed desaturation in both groups had a history of smoking or pulmonary disease, or a BMI $>30 \mathrm{~kg} \cdot \mathrm{m}^{-2}$. Caution should be exercised when administering sedation in such patients.

We found that the proportion of patients who recalled airway management was higher in the remifentanil group than the dexmedetomidine group. This finding chimes with those of previous studies, which have reported that

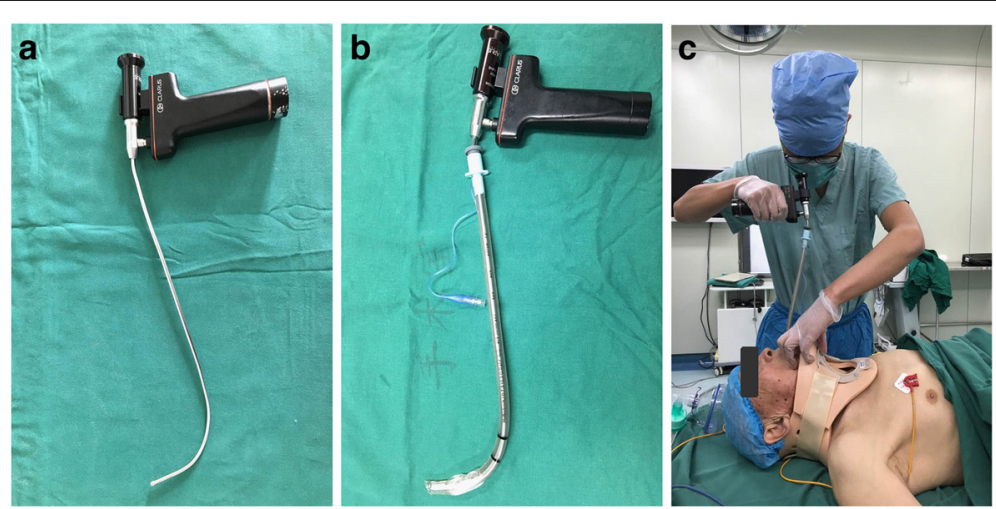

Fig. 2 Shikani Optical Stylet larygngoscope and its application in a male patient with hard plastic collar. a A Shikani Optical Stylet larygngoscope; (b) The Shikani Optical Stylet larygngoscope was inserted into an endotracheal tube; (c) Manipulation of tracheal intubation by a Shikani Optical Stylet larygngoscope 
dexmedetomidine has a stronger amnesic effect than remifentanil $[9,10]$. Although the recall rate was higher in Group R, most patients did not find the experience unpleasant, reflected in broadly comparable patient satisfaction scores. Although no dental injuries were reported in our study, there was a high incidence of sore throat in both groups $(47.1 \%$ versus $52.9 \%, P=0.628)$, which may have been a consequence of surgery rather than airway instrumentation. It has previously been reported that the incidence of sore throat was as high as $51-74 \%$ in patients undergoing cervical spine surgery [32].

Our study had some limitations. First, the sample size in each group was 34 and the primary endpoint was first-attempt intubation success rate. These were 79.4 and $85.3 \%$ in each group, meaning that the risk of a statistical type II error was 0.88 . Therefore, further larger samples studies will be needed to confirm our results. Second, there was also a relatively high chance that our sample size was inadequate to detect intergroup differences for uncommon adverse events (e.g., lip or teeth injuries, complications associated with oxygen desaturation events, etc.). Finally, our results cannot be extrapolated to settings where target-controlled infusion of remifentanil is not available.

\section{Conclusions}

Dexmedetomidine and remifentanil are effective sedatives for awake intubation using the SOS. Although the firstattempt success rates were similar between the two groups, patients sedated with remifentanil tolerated the ETT better at the expense of an increased risk of mild hypoxia.

\section{Abbreviations}

AFOI, awake fiberoptic endoscope intubation; DBP, diastolic blood pressure $E T$, endotracheal tube; FOB, fiberoptic endoscope; HR, heart rate; RSS, Ramsay Sedation Scale; SBP, systolic blood pressure; SOS, Shikani optical stylet; $\mathrm{TCl}$, target controlled infusion

\section{Acknowledgments}

We sincerely thank all the staff of the Anesthesiology Department of Peking university third hospital for their help in this research.

\section{Funding}

Not applicable.

\section{Availability of data and materials}

The data during this study are available from the corresponding author on reasonable request.

\section{Authors' contributions}

All authors have made substantive intellectual contributions to the manuscript. $\mathrm{ML}$ and TX designed the study. TX and CN were responsible for conducting the study and analyzing the data. ML, TX and CN wrote the manuscript. XG participated in study design and revised the manuscript. All authors have seen the original study data, reviewed the data analysis and approved the final manuscript.

\section{Competing interests}

The authors declare that they have no competing interests.

\section{Consent for publication}

Written informed consent was obtained from the patient for publication of the Fig. $2 c$ in this article.

\section{Ethics approval and consent to participate}

The study was approved by Peking university third hospital medical ethics committee and each participant provided written informed consent.

Received: 11 December 2015 Accepted: 28 July 2016

Published online: 02 August 2016

\section{References}

1. Lin N, Li M, Shi S, Li TZ, Zhang BX. Shikani seeing optical stylet-aided tracheal intubation in patients with a large epiglottic cyst. Chin Med J (Engl). 2011;124:2795-8.

2. Phua DS, Mah CL, Wang CF. The Shikani optical stylet as an alternative to the GlideScope ${ }^{\circledast}$ videolaryngoscope in simulated difficult intubations-a randomised controlled trial. Anaesthesia. 2012;67:402-6.

3. Shukry M, Hanson RD, Koveleskie JR, Ramadhyani U. Management of the difficult pediatric airway with Shikani Optical Stylet. Paediatr Anaesth. 2005;15:342-5.

4. Stricker P, Fiadjoe JE, McGinnis S. Intubation of an infant with Pierre Robin sequence under dexmedetomidine sedation using the Shikani Optical Stylet. Acta Anaesthesiol Scand. 2008:52:866-7.

5. Agro F, Cataldo R, Carassiti M, Costa F. The seeing stylet: a new device for tracheal intubation. Resuscitation. 2000:44:177-80.

6. Yang D, Tong SY, Jin JH, Tang GZ, Sui JH, Wei LX, Deng XM. Shikani optical stylet-guided intubation via the intubating laryngeal airway in patients with scar contracture of the face and neck. Chin Med Sci J. 2013;28:195-200.

7. Turkstra TP, Pelz DM, Shaikh AA, Craen RA. Cervical spine motion: a fluoroscopic comparison of Shikani Optical Stylet vs Macintosh laryngoscope. Can J Anaesth. 2007:54:441-7.

8. Kovacs G, Law AJ, Petrie D. Awake fiberoptic intubation using an optical stylet in an anticipated difficult airway. Ann Emerg Med. 2007:49:81-3.

9. Hu R, Liu JX, Jiang H. Dexmedetomidine versus remifentanil sedation during awake fiberoptic nasotracheal intubation: a double-blinded randomized controlled trial. J Anesth. 2013:27:211-7.

10. Cattano D, Lam NC, Ferrario L, Seitan C, Vahdat K, Wilcox DW, Hagberg CA. Dexmedetomidine versus remifentanil for sedation during awake fiberoptic intubation. Anesthesiol Res Pract. 2012;2012:753107.

11. Boyd BC, Sutter SJ. Dexmedetomidine sedation for awake fiberoptic intubation of patients with difficult airways due to severe odontogenic cervicofacial infections. J Oral Maxillofac Surg. 2011;69:1608-12.

12. Bergese SD, Candiotti KA, Bokesch PM, Zura A, Wisemandle W, Bekker AY, Group AS. A Phase IIIb, randomized, double-blind, placebo-controlled, multicenter study evaluating the safety and efficacy of dexmedetomidine for sedation during awake fiberoptic intubation. Am J Ther. 2010;17:586-95.

13. Bergese SD, Patrick Bender S, McSweeney TD, Fernandez S, Dzwonczyk R, Sage K. A comparative study of dexmedetomidine with midazolam and midazolam alone for sedation during elective awake fiberoptic intubation. I Clin Anesth. 2010;22:35-40.

14. Kunisawa T, Nagashima M, Hanada S, Suzuki A, Takahata O, Iwasaki H. Awake intubation under sedation using target-controlled infusion of dexmedetomidine: five case reports. J Anesth. 2010;24:789-92.

15. Chu KS, Wang FY, Hsu HT, Lu IC, Wang HM, Tsai CJ. The effectiveness of dexmedetomidine infusion for sedating oral cancer patients undergoing awake fibreoptic nasal intubation. Eur J Anaesthesiol. 2010;27:36-40.

16. Tsai CJ, Chu KS, Chen TI, Lu DV, Wang HM, Lu IC. A comparison of the effectiveness of dexmedetomidine versus propofol target-controlled infusion for sedation during fibreoptic nasotracheal intubation. Anaesthesia. 2010:65:254-9.

17. Shen SL, Xie Y, Wang WY, Hu SF, Zhang YL. Comparison of dexmedetomidine and sufentanil for conscious sedation in patients undergoing awake fibreoptic nasotracheal intubation: a prospective, randomised and controlled clinical trial. Clin Respir J. 2014;8:100-7.

18. Madhere M, Vangura D, Saidov A. Dexmedetomidine as sole agent for awake fiberoptic intubation in a patient with local anesthetic allergy. I Anesth. 2011:25:592-4.

19. Abdelmalak B, Makary L, Hoban J, Doyle DJ. Dexmedetomidine as sole sedative for awake intubation in management of the critical airway. J Clin Anesth. 2007:19:370-3. 
20. Gaszynski T, Gaszynska E, Szewczyk T. Dexmedetomidine for awake intubation and an opioid-free general anesthesia in a superobese patient with suspected difficult intubation. Drug Des Devel Ther. 2014;8:909-12.

21. Bergese SD, Khabiri B, Roberts WD, Howie MB, McSweeney TD, Gerhardt MA. Dexmedetomidine for conscious sedation in difficult awake fiberoptic intubation cases. J Clin Anesth. 2007;19:141-4.

22. Bloor BC, Ward DS, Belleville JP, Maze M. Effects of intravenous dexmedetomidine in humans. II. Hemodynamic changes. Anesthesiology. 1992;77:1134-42.

23. Lallo A, Billard V, Bourgain JL. A comparison of propofol and remifentanil target-controlled infusions to facilitate fiberoptic nasotracheal intubation. Anesth Analg. 2009;108:852-7.

24. Lee HM, Sakong J, Jee DL. The comparison of feasibility and safety on fiberoptic guided intubation under conscious sedation with remifentanil and propofol. Korean J Anesthesiol. 2013;65:215-20.

25. Rai MR, Parry TM, Dombrovskis A, Warner OJ. Remifentanil target-controlled infusion vs propofol target-controlled infusion for conscious sedation for awake fibreoptic intubation: a double-blinded randomized controlled trial. Br J Anaesth. 2008;100:125-30.

26. Cafiero T, Esposito F, Fraioli G, Gargiulo G, Frangiosa A, Cavallo LM, Mennella $\mathrm{N}$, Cappabianca P. Remifentanil-TCl and propofol-TCl for conscious sedation during fibreoptic intubation in the acromegalic patient. Eur J Anaesthesiol. 2008;25:670-4

27. Zhang X, He W, Wu X, Zhou X, Huang W, Feng X. TCl remifentanil vs. TCI propofol for awake fiber-optic intubation with limited topical anesthesia. Int J Clin Pharmacol Ther. 2012;50:10-6.

28. Song JW, Kwak YL, Lee JW, Chang CH, Kim HS, Shim YH. The optimal effect site concentration of remifentanil in combination with intravenous midazolam and topical lidocaine for awake fibreoptic nasotracheal intubation in patients undergoing cervical spine surgery. Minerva Anestesiol. 2012;78:521-6.

29. Vennila R, Hall A, Ali M, Bhuiyan N, Pirotta D, Raw DA. Remifentanil as single agent to facilitate awake fibreoptic intubation in the absence of premedication. Anaesthesia. 2011;66:368-72.

30. Yeganeh N, Roshani B, Azizi B, Almasi A. Target-controlled infusion of remifentanil to provide analgesia for awake nasotracheal fiberoptic intubations in cervical trauma patients. J Trauma. 2010;69:1185-90.

31. Sinha SK, Joshiraj B, Chaudhary L, Hayaran N, Kaur M, Jain A. A comparison of dexmedetomidine plus ketamine combination with dexmedetomidine alone for awake fiberoptic nasotracheal intubation: a randomized controlled study. J Anaesthesiol Clin Pharmacol. 2014;30:514.

32. Ratnaraj J, Todorov A, McHugh T, Cheng MA, Lauryssen C. Effects of decreasing endotracheal tube cuff pressures during neck retraction for anterior cervical spine surgery. J Neurosurg. 2002;97:176-9.

\section{Submit your next manuscript to BioMed Central and we will help you at every step:}

- We accept pre-submission inquiries

- Our selector tool helps you to find the most relevant journal

- We provide round the clock customer support

- Convenient online submission

- Thorough peer review

- Inclusion in PubMed and all major indexing services

- Maximum visibility for your research

Submit your manuscript at www.biomedcentral.com/submit

C Biomed Central 